\title{
A comprehensive dairy valorization model
}

\author{
A. Banaszewska, ${ }^{*} \dagger^{1}$ F. Cruijssen, ${ }^{*}$ J. G. A. J. van der Vorst, ${ }^{*}$ G. D. H. Claassen, ${ }^{*}$ and J. L. Kampman $\dagger$ \\ *Logistics, Decision and Information Sciences, Wageningen University and Research Centre, Hollandseweg 1, 6706 KN Wageningen, \\ the Netherlands \\ †FrieslandCampina, Stationsplein 4, 3818 LE Amersfoort, the Netherlands
}

\begin{abstract}
Dairy processors face numerous challenges resulting from both unsteady dairy markets and some specific characteristics of dairy supply chains. To maintain a competitive position on the market, companies must look beyond standard solutions currently used in practice. This paper presents a comprehensive dairy valorization model that serves as a decision support tool for mid-term allocation of raw milk to end products and production planning. The developed model was used to identify the optimal product portfolio composition. The model allocates raw milk to the most profitable dairy products while accounting for important constraints (i.e., recipes, composition variations, dairy production interdependencies, seasonality, demand, supply, capacities, and transportation flows). The inclusion of all relevant constraints and the ease of understanding dairy production dynamics make the model comprehensive. The developed model was tested at the international dairy processor FrieslandCampina (Amersfoort, the Netherlands). The structure of the model and its output were discussed in multiple sessions with and approved by relevant FrieslandCampina employees. The elements included in the model were considered necessary to optimally valorize raw milk. To illustrate the comprehensiveness and functionality of the model, we analyzed the effect of seasonality on milk valorization. A large difference in profit and a shift in the allocation of milk showed that seasonality has a considerable impact on the valorization of raw milk.
\end{abstract}

Key words: raw milk, valorization, production planning, allocation

\section{INTRODUCTION}

Dairy processors face numerous challenges resulting both from unsteady dairy markets and from specific characteristics of dairy supply chains. The volatility of demand and prices of dairy products, greater competi-

Received April 19, 2012

Accepted October 15, 2012.

${ }^{1}$ Corresponding author: agata.banaszewska@wur.nl tiveness, and the increasing regulations that limit access to external markets significantly affect the performance of dairy processors. The European dairy sector is under constant change following, for example, the new European Union (EU) dairy policy and the outcomes of ongoing negotiations in the World Trade Organization. In 2003, the intervention prices for butter and skim milk powder (SMP) were decreased by 25 and $15 \%$, respectively. Intervention prices act as floor market prices; that is, every national intervention agency in the $\mathrm{EU}$ is obliged to purchase, for this price, any amount of dairy commodity offered to them by dairy companies (Womach, 2005). The substantial decline in the intervention price made the production of bulk products less profitable and more risky. Furthermore, in 2003, it was decided to gradually increase milk quotas and completely abolish them in 2015 . These changes led to, and likely will continue to lead to, an increase in milk supply. Furthermore, in the last years, the price of milk fluctuated between $€ 27$ and $€ 35$ per $100 \mathrm{~kg}$. The yearly percentage change in price in 2000 to 2010 reached $22 \%$ (LTO, 2011). According to Geary et al. (2010), dairy market fluctuations and price volatility will be a constant challenge to the future dairy industry. Additionally, the enlargement of the EU in 2007 increased the competitiveness on the EU dairy market, thereby making the market more difficult for dairy processors. High competitiveness on the international dairy market requires dairy processors to optimize production and sales to ensure survival (Guan and Philpott, 2011).

The complexity emerging from the uniqueness of dairy supply chains also requires advanced methods for effective dairy supply chain management. In a dairy chain, raw milk (RM), the main raw material, is collected from multiple dairy farms scattered throughout the supply area and used for the production of all dairy products. The volume and, in part, the choice of end product (EP) to be produced depend on the nutrient content of RM, which changes during the year. The production of dairy products is interrelated: a byproduct (BP) of one production process can be used in another production process, which often takes place at a different location. To manage the incoming milk profitably, 
efficient logistics in many domains are required; for example, transport, allocation, and production planning.

A comprehensive model that captures the dynamics of dairy production and incorporates all relevant constraints related to internal and external environments would significantly improve allocation of milk. The results of the literature review provided in the next section clearly indicate the lack of such a model in current use. In this paper, we present a comprehensive dairy valorization model (DVM) that optimizes mid-term plans for the allocation of RM and the production of EP and BP while considering all constraints. The model captures all factors that directly or indirectly influence the allocation of RM. Furthermore, the comprehensiveness of the model allows producers to understand the effect of various changing parameters on milk valorization. This is an important advantage, given the constant changes on the dairy market and in the RM supply. The model not only improves milk valorization, therefore, but also provides a good understanding of prevailing production processes. The developed model was verified at the international dairy processor FrieslandCampina (FC; Amersfoort, the Netherlands).

We will first present a literature overview and then present the model in 3 steps. First, the conceptual model will be described, then the model will be verified using information from FC, and finally the mathematical model will be formulated. We will discuss the main outcomes of the model and then define and conduct an additional scenario that evaluates the impact of RM seasonality on valorization.

\section{Literature Review}

The literature provides various approaches to maximize profit of dairy producers, starting from a general analysis of dairy manufacturing processes (Roupas, 2008), through allocation models that capture parts of the production process (Kerrigan and Norback, 1986; Papadatos et al., 2002; Burke, 2006; Doganis and Sarimveis, 2007), allocation models that aim to allocate milk to all dairy products in a portfolio (Mellalieu and Hall, 1983; Benseman, 1986), and models that represent whole dairy supply chains (Wouda et al., 2002; Vaklieva-Bancheva et al., 2007; Guan and Philpott, 2011). Given the purpose of this paper and the specific characteristics of the dairy supply chain, we have focused on papers presenting models that aim at the allocation of RM to final dairy products. Readers interested in complete state-of-the-art production planning models may refer to the following review papers: production-distribution models (Vidal and Goetschalckx, 1997; Bilgen and Ozkarahan, 2004; Chen, 2004; Ahumada and Villalobos, 2009), mainte- nance and production (Budai et al., 2008), production planning and uncertainty (Sahinidis, 2004; Mula et al., 2006; Wazed et al., 2010), production and transport (Mula et al., 2010), and predictive modeling of manufacturing processes (Roupas, 2008).

Even though the dairy production problem has been treated in many ways, a model that takes into account all factors necessary to create a comprehensive DVM is, to the best of our knowledge, not yet available in the literature. A complete list of important factors affecting the valorization of RM was identified, based on a literature study and interviews with experts. Models available in the literature and focusing on the allocation of RM to EP were investigated with respect to included factors. To verify the list of factors, we studied in detail the environment and processes of one of the world's largest dairy companies (FC). Additionally, iterative sessions were held with dairy supply chain managers, production planners, technologists, and market analysts at FC. During these sessions, intermediate results were discussed. This pragmatic stepwise approach of literature and process analyses resulted in the final list of factors (Table 1).

To investigate the models presented in the literature, we began with the framework developed by Ahumada and Villalobos (2009) and extended it with model features that are especially relevant for mid-term dairy production planning. Additionally, we looked at the applicability of these models in practice. We analyzed the papers with respect to the following characteristics: modeling technique; modeling approach (deterministic or stochastic); planning horizon (single period, shortterm, mid-term, or long-term); recipes based on milk composition (yes or no); seasonality of RM composition and RM supply included (yes or no); part of product portfolio covered - whole product portfolio (yes) or a particular product group (no; e.g., cheeses or yogurts); $\mathrm{BP}$ reutilization (yes or no); BP transport (yes or no); RM transport (yes or no); network of supply regions and production locations (yes or no); changes in product prices - throughout the whole planning horizon, within planning periods that determine the complete planning horizon, and no changes included (no); model tested on a real-life case - application (yes or no). The results of the analysis are presented in Table 2. As can be seen, none of the models available in the literature included all factors relevant to efficient milk valorization. A milk allocation model that included most of the important features was developed more than 25 yr ago (Benseman, 1986). The seasonality aspect of milk components was partly incorporated in that model; that is, volumes of EP obtained from $1 \mathrm{t}$ of RM depend on the composition of milk; however, volumes of BP are fixed. In reality, this is not true because milk composition affects both 
Table 1. Factors relevant for milk valorization

Factor
1. Recipes based on raw milk composition
2. Seasonality of raw milk composition and supply

3. Whole product portfolio

4. Byproduct utilization

5. Network of supply regions and production locations 6. Byproduct transportation

7. Raw milk transportation

8. Changes in prices
Relevance for milk valorization

The inclusion of factors 1 and 2 allows the model to capture the changing composition of products, which is influenced by the seasonal composition of raw milk. Because all products are originally produced from raw milk, the composition of input material influences the type or volume of end product that is obtained.

Products that cover the whole product portfolio as well as the resulting byproducts should be taken into account during optimization. This guarantees that raw milk is always allocated to the best valorizing dairy products.

The production of dairy products is interrelated. Often a byproduct of a certain process can be used as an input for another process. Consequently, the flow of byproducts between various products and factories might have a significant effect on allocation decisions as well as on available capacity.

Large volumes of raw milk and byproducts have to be transported every day. Allocation decisions might be different depending on the distance between a supply region or a source production location at which an input material is available and destination production locations at which that input material is required. Consequently, transport costs might influence valorization of milk.

Market developments should also be incorporated in the model. In particular, changes in prices from one planning period to another and changes during the planning periods resulting from price elasticity (different volumes sold for different prices) should be incorporated.
EP and BP volumes. Furthermore, only a small part of the current set of dairy products and BP was covered in Benseman (1986), and no explicit relation between EP and BP was provided. Additionally, it was not possible to use multiple production recipes. The model did not allow for the possibility of selling and purchasing RM. Finally, only changes in prices throughout the planning horizon (from one planning period to the next) were incorporated. It was assumed, however, that the sale price of an EP remained constant within a planning period. Consequently, no price elasticity reflecting a relationship between prices and volumes was taken into account. Other papers that incorporated a larger number of relevant factors are Mellalieu and Hall (1983), Vaklieva-Bancheva et al. (2007), and Guan and Philpott (2011).

In the model developed by Mellalieu and Hall (1983), it was not clear which part of the dairy portfolio was included. The relation between EP and BP was not indicated. A network of supply regions and locations was incorporated, but it was used only for the transportation of RM. Byproducts were not reused in the production process. Because the production of dairy products is interrelated, excluding the possibility of using BP as inputs for further production results in suboptimal solutions. The model developed by Vaklieva-Bancheva et al. (2007) aimed at evaluating an existing compromise between actors of the dairy supply chain. It was not a tool designed specifically to optimize production planning, and a very limited number of products was introduced in the model. Therefore, the relation between the current set of EP and BP was missing. The possibility of reusing $\mathrm{BP}$ was also limited and no transportation of $\mathrm{BP}$ was allowed. Although product recipes depend on the composition of $\mathrm{RM}$, the model failed to fully incorporate the aspect of RM seasonality and price variability. The model recently developed by Guan and Philpott (2011) incorporated uncertainty in milk supply, price--demand relations, and contracting. A large part of the paper was focused on uncertainty in the milk supply, and little attention was given to the representation of the dairy portfolio. Consequently, it is not known which products were incorporated in the model, no BP flows were included, and recipes were not based on RM composition. Thus, the seasonality of milk was included only via volumes supplied throughout the year. Including seasonality, however, would improve the effectiveness of such models, making them a more useful, year-round, decision-support tool (Geary et al., 2010). The results of the literature research conducted in this study and presented in Table 2 confirmed the lack of a model that includes all relevant factors affecting milk valorization. Therefore, a comprehensive DVM that incorporates all the important aspects, as developed in this study, would fill this literature gap.

\section{MATERIALS AND METHODS}

To develop the DVM, we used several methods: literature research, interviews, and linear programming. In the first phase of the study, including literature research and interviews, we determined the most im- 


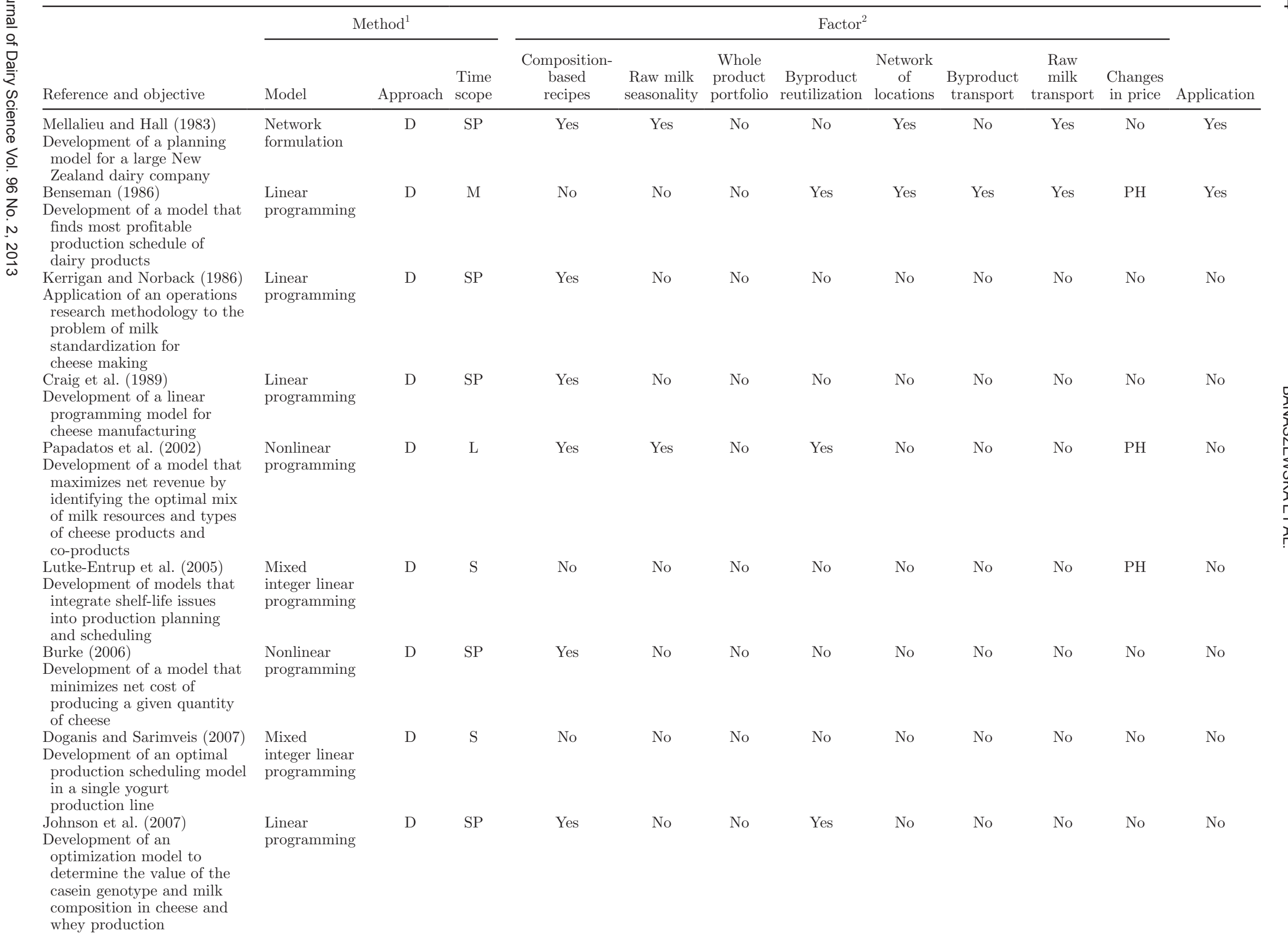


Table 2 (Continued). Literature overview-dairy production planning models

\begin{tabular}{|c|c|c|c|c|c|c|c|c|c|c|c|c|}
\hline \multirow[b]{2}{*}{ Reference and objective } & \multicolumn{3}{|c|}{ Method $^{1}$} & \multicolumn{8}{|c|}{ Factor $^{2}$} & \multirow[b]{2}{*}{ Application } \\
\hline & Model & Approach & $\begin{array}{l}\text { Time } \\
\text { scope }\end{array}$ & $\begin{array}{l}\text { Composition- } \\
\text { based } \\
\text { recipes }\end{array}$ & $\begin{array}{c}\text { Raw milk } \\
\text { seasonality }\end{array}$ & $\begin{array}{l}\text { Whole } \\
\text { product } \\
\text { portfolio }\end{array}$ & $\begin{array}{l}\text { Byproduct } \\
\text { reutilization }\end{array}$ & $\begin{array}{l}\text { Network } \\
\text { of } \\
\text { locations }\end{array}$ & $\begin{array}{l}\text { Byproduct } \\
\text { transport }\end{array}$ & $\begin{array}{c}\text { Raw } \\
\text { milk } \\
\text { transport }\end{array}$ & $\begin{array}{l}\text { Changes } \\
\text { in price }\end{array}$ & \\
\hline $\begin{array}{l}\text { Vaklieva-Bancheva et al. } \\
\text { (2007) } \\
\text { Evaluation of existing } \\
\text { compromise between the } \\
\text { dairy supply chain actors, } \\
\text { by developing a } \\
\text { mathematical model }\end{array}$ & $\begin{array}{l}\text { Multi objective } \\
\text { optimization } \\
\text { model }\end{array}$ & $\mathrm{D}$ & SP & Yes & No & No & Yes & Yes & No & Yes & No & No \\
\hline $\begin{array}{l}\text { Doganis and Sarimveis (2008) } \\
\text { Development of a customized } \\
\text { model for optimizing yogurt } \\
\text { packaging lines }\end{array}$ & $\begin{array}{l}\text { Mixed } \\
\text { integer linear } \\
\text { programming }\end{array}$ & $\mathrm{D}$ & $\mathrm{S}$ & No & No & No & No & No & No & No & No & Yes \\
\hline $\begin{array}{l}\text { Adonyi et al. (2009) } \\
\text { Presentation of two } \\
\text { independent approaches } \\
\text { for obtaining minimal } \\
\text { makespan schedule }\end{array}$ & $\begin{array}{l}\text { Two } \\
\text { approaches: } \\
\text { (1) s-graph } \\
\text { framework } \\
\text { with branch } \\
\text { and bound, } \\
\text { (2) ip with } \\
\text { basic genetic } \\
\text { algorithm }\end{array}$ & $\mathrm{D}$ & S & Yes & No & No & No & No & No & No & No & No \\
\hline $\begin{array}{l}\text { Guan and Philpott (2011) } \\
\text { Development of a multistage } \\
\text { stochastic programming } \\
\text { model }\end{array}$ & $\begin{array}{l}\text { Multistage } \\
\text { stochastic } \\
\text { programming }\end{array}$ & $\mathrm{S}$ & M & No & No & Yes & No & Yes & No & Yes & $\begin{array}{c}\mathrm{PH} \text { and } \\
\mathrm{PP}\end{array}$ & Yes \\
\hline $\begin{array}{l}\text { Geary et al. (2010) } \\
\text { Development of a processing- } \\
\text { sector model that simulates: } \\
\text { (1) milk collection, } \\
\text { (2) standardization, and } \\
\text { (3) product manufacture }\end{array}$ & $\begin{array}{l}\text { Mass balance } \\
\text { model }\end{array}$ & $\mathrm{D}$ & $\mathrm{SP}$ & Yes & No & Yes & Yes & No & No & No & No & Yes \\
\hline
\end{tabular}

${ }^{1}$ Approach: $\mathrm{D}=$ deterministic; $\mathrm{S}=$ stochastic; Time scope: $\mathrm{SP}=$ single period; $\mathrm{M}=$ mid-term; $\mathrm{L}=$ long-term; $\mathrm{S}=$ short-term.

${ }^{2}$ Changes in price: $\mathrm{PP}=$ within planning periods that determine the complete planning horizon; $\mathrm{PH}=$ throughout the whole planning horizon. 


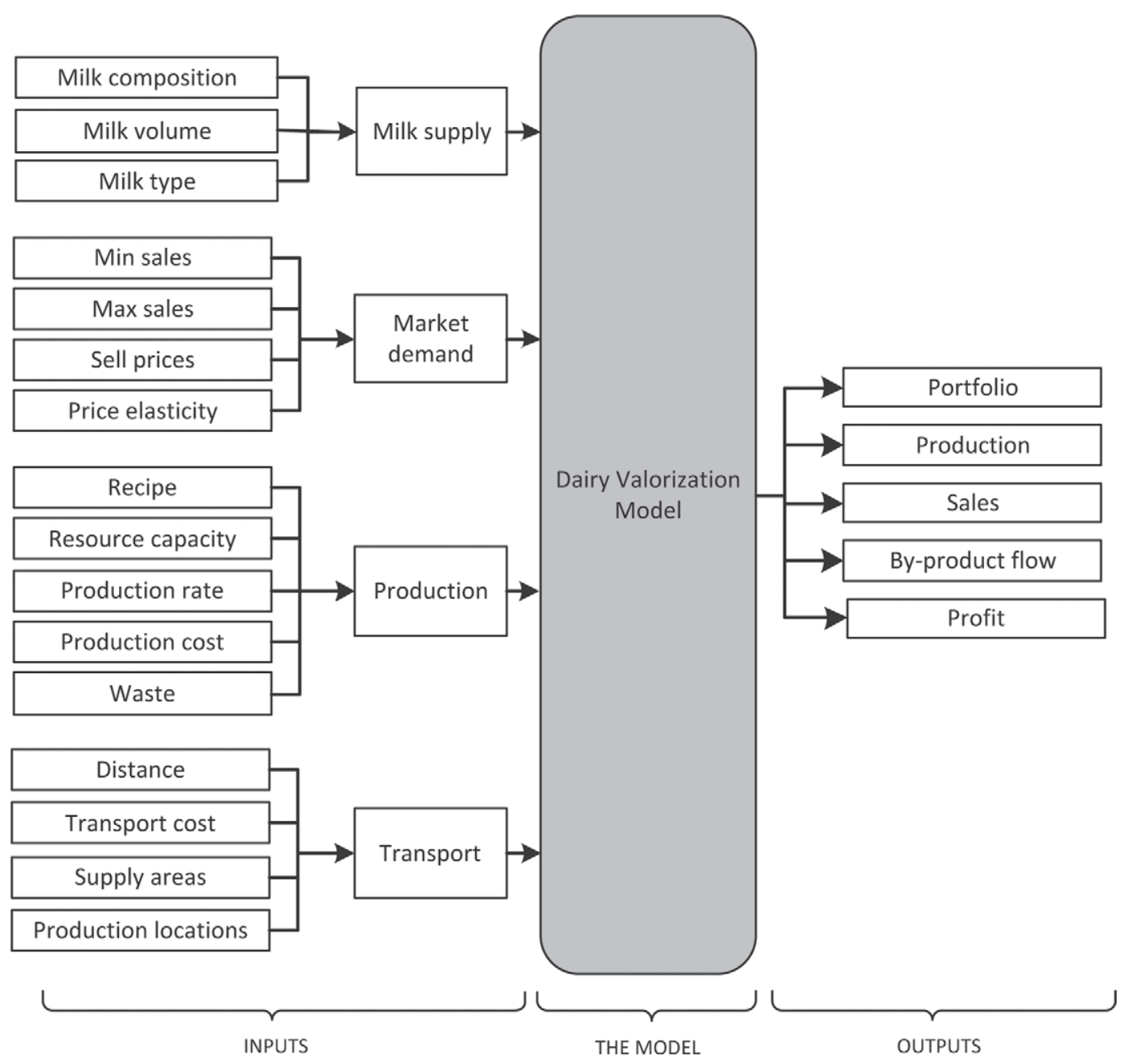

Figure 1. Scheme of the dairy valorization model.

portant factors that should be included in the model. Furthermore, we described in detail and analyzed all relevant processes to define the constraints of the system. The relevant research papers were analyzed in a structured way with regard to the methodology used, factors included, and application. Additionally, multiple sessions with relevant experts - dairy supply chain managers, production planners, technologists, and market analysts - were held over a year. During these sessions, parameters and constraints that should be included in the model, recipes, and product interrelations were discussed. Finally, the information gathered in the first phase of the research was used to build the model. We used a linear programming method to describe the problem at hand. Following the methodology, we defined the objective and constraints of the problem, and formulated it mathematically. To validate the model we compared 2 scenarios using real data sets supplied by
FC. All results were discussed during iterative sessions with experts and their reliability was approved.

\section{Conceptual Model Description}

Model Elements. To create an advanced DVM for the mid-term production planning, elements related to external and internal environments should be taken into account. Factors relevant to valorization were presented in the previous section. Based on these factors, we created a scheme of the DVM (Figure 1). The scheme of the model was discussed with experts and its completeness confirmed. The model uses various inputs to create valorization plans. These plans determine the volumes of RM that should be allocated to EP in every period. Every run of the model provides a valorization plan for several consecutive periods, which together form a planning horizon. 


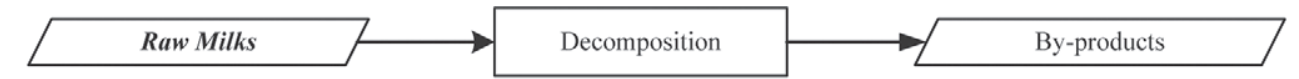

Step 1: Decomposition

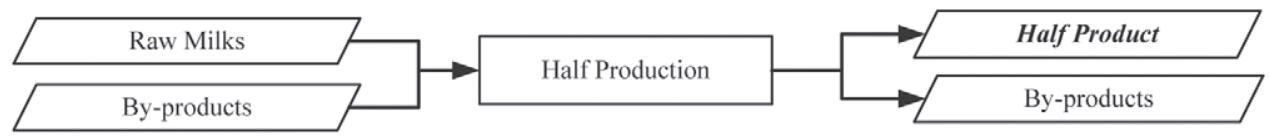

Step 2: Half Production

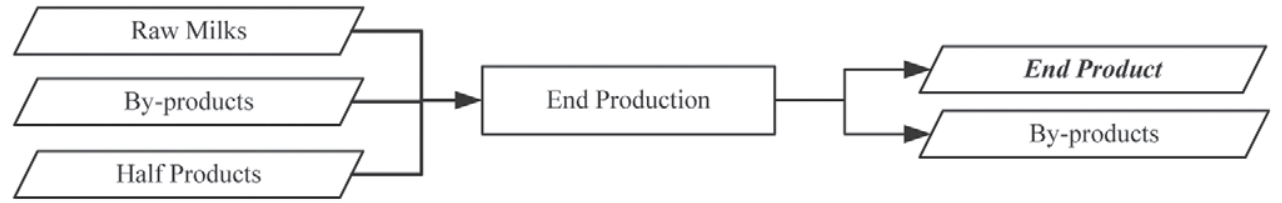

Step 3: End Production

Figure 2. Production stages.

The inputs of the model consisted of elements related to milk supply, market demand, production, and transport. Elements included in the milk supply group ensure that the seasonality and composition of the RM supply are included. Elements of market demand group reflect the situation on the dairy market. Price elasticity was captured by means of tranches that indicate volume and price for which a product can be sold. The first tranche represents volumes of products fixed in contracts, together with the average contract sale prices. The residual tranches reflect the situation on the market; that is, the greater the volume of product placed on the market (sold), the lower the selling price. Consequently, the prices assigned to tranches other than the first tranche decrease. The price assigned to the first tranche depends on the contracts that were made in the past. Elements of the production group represent parameters related to dairy production. Waste elements represent a loss of components during the production process. More information on waste is provided in the next subsection. Elements included in the transport group allow for the optimization of flows of $\mathrm{BP}$ required for production. The main output of the model is a production plan resulting from the valorized allocation of RM. The optimal production plan is represented by the highest possible profit, and thus the best valorization of milk components. Furthermore, no parameters related to inventory management were included in the DVM. Although inventory is often one of the elements of production planning models, most models developed for the dairy industry do not incorporate the inventory management problem (Papadatos et al., 2002; Burke, 2006; Doganis and Sarimveis, 2007; Johnson et al., 2007; Vaklieva-Bancheva et al., 2007; Adonyi et al., 2009; Geary et al., 2010). The reason behind this, from the perspective of a mid-term model, could be the relatively short shelf life of dairy products. Therefore, we decided not to include inventory management options in the model developed in this study, but instead to focus on a detailed investigation of production planning processes. For the same reason, we decided to use a deterministic approach. A stochastic approach would perhaps allow better capturing of the volatility of variable parameters, but the complexity of such a model would be much higher than that of a deterministic model. Nevertheless, inclusion of stochastic elements in the comprehensive DVM is an interesting and challenging topic for the future research.

Production of Dairy Products. The DVM was designed to optimize the production at dairy processors by allocating all incoming RM to the most profitable EP. All products were clustered into 4 categories: RM, BP, half products (HP), and EP. Byproducts are the products additionally obtained while producing main products; that is, HP and EP. Furthermore, cream and skim milk can be also obtained from a decomposition of RM. Half products are the intermediate products necessary for the production of EP. The EP are produced by means of a production process, which is divided into 3 stages: decomposition, half production, and end production (Figure 2). The main reason for decoupling the production process into 3 stages is the availability of capacities at various locations. For instance, production of butter requires cream as an input. If a butter 


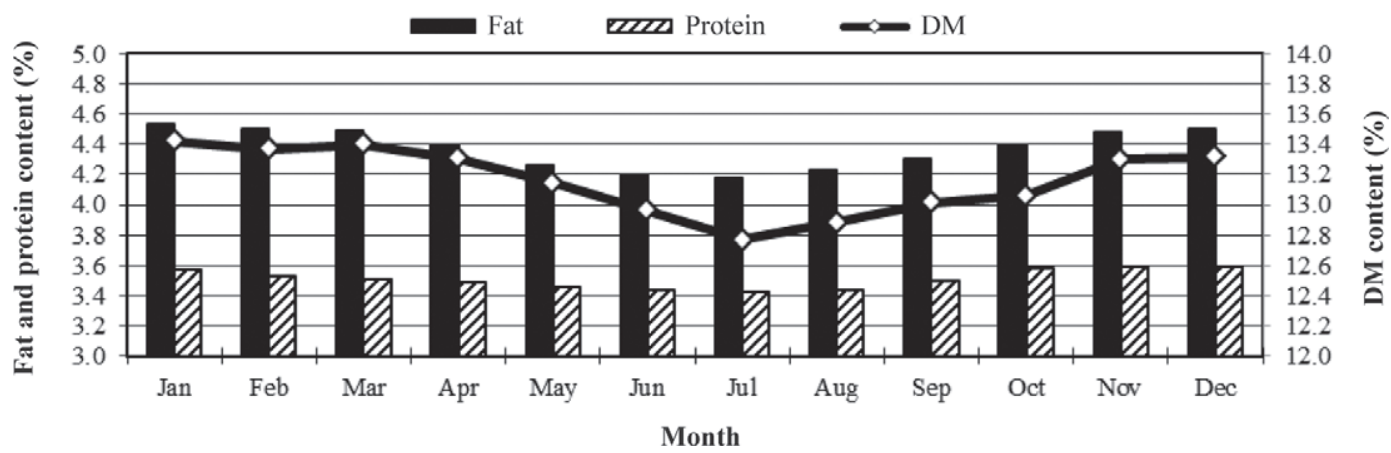

Figure 3. Composition of raw milk throughout the year (source: FrieslandCampina, Amersfoort, the Netherlands).

location does not have separation equipment, cream could be obtained from another location. Therefore, the introduction of production stages in the optimization model contributes to a reduction in total transportation costs and to optimal use of production capacities.

Every product can be produced with the use of multiple recipes. A recipe includes the information on the type, volume, and composition of inputs used in and outputs obtained from the production. The composition of EP is mostly fixed; that is, a certain level of DM, fat, and protein. In certain situations, only selected components must match a specified level, whereas others must fulfill a minimum level. The desired component levels are obtained by means of a standardization technique that calculates fractions; that is, volumes of input materials required to obtain $1 \mathrm{t}$ of product with a desired composition level. Because the composition of RM throughout the year (see Figure 3), volumes required and obtained from production also change. A crucial part of the production process is to ensure that the volume of a component in all inputs equals the volume of that component in all outputs. The value of RM lies in its components; hence, every kilogram of inefficiently used component is a loss for a manufacturer. Waste products are introduced in the model to track inefficiently used volumes of components.

\section{Case Study: FrieslandCampina}

FrieslandCampina is one of the largest dairy companies and the largest dairy cooperative in the world (2011 sales amounted to around €9.5 billion). The company has approximately 14,500 member dairy farms that deliver almost 9 billion kilograms of RM yearly. This milk is transformed into a wide range of EP; for example, milk-based drinks, cheese, yogurts, milk powders, dairy-based ingredients, infant food, and animal feed. To process all RM and to market EP, the company employs 19,000 people in 25 countries. Final products are delivered to more than 100 countries worldwide; key regions are Europe, Asia, and Africa (FrieslandCampina, 2011). The aim of FC is to become the world's most professional, successful, and attractive global dairy company by "getting more out of milk." Because milk is the main raw material used for the production of all FC's products, the focus is on complete $\mathrm{RM}$ valorization; that is, 3-level valorization. The highest level of valorization takes place on a strategic level. Here, general plans for high-level dairy production are defined. The DVM is used to prepare plans for the next level (the tactical level). Finally, the output

Table 3. Dairy products in the dairy valorization model

\begin{tabular}{ll}
\hline Product (abbreviation) & Group \\
\hline Butter milk powder (BMP) & End product \\
Butter & End product \\
Butter oil & End product \\
Caseinate roller & End product \\
Caseinate spray & End product \\
Cheese foil & End product \\
Cheese nature & End product \\
Cream product (CreamProd) & End product \\
Evaporated milk (EVAP) & End product \\
Infant food and growing-up milk powder & End product \\
(IF/GUM) & \\
Instant full cream milk powder (IFCMP) & End product \\
Sweet condensed milk (SCM) & End product \\
Serum powder & End product \\
Skim milk concentrate product & End product \\
(SkimMilkConcProd) & \\
Skim milk product (SkimMilkProd) & End product \\
Skim milk powder (SMP) & End product \\
Standardized milk (StdMilk) & End product \\
Whole milk powder (WMP) & End product \\
Raw milk & Raw milk \\
Butter milk & Byproduct \\
Cream & Byproduct \\
Cream serum & Byproduct \\
Lactose & Byproduct \\
Retentate & Byproduct \\
Skim milk & Byproduct \\
Whey casein & Byproduct \\
Whey cheese & Byproduct \\
Cheese milk foil (ChMFoil) & Half product \\
Cheese milk nature (ChMNature) & Half product \\
Protein standardized skim milk (ProStdSM) & Half product \\
Skim milk concentrate (SkimMilkConc) & Half product \\
\hline
\end{tabular}



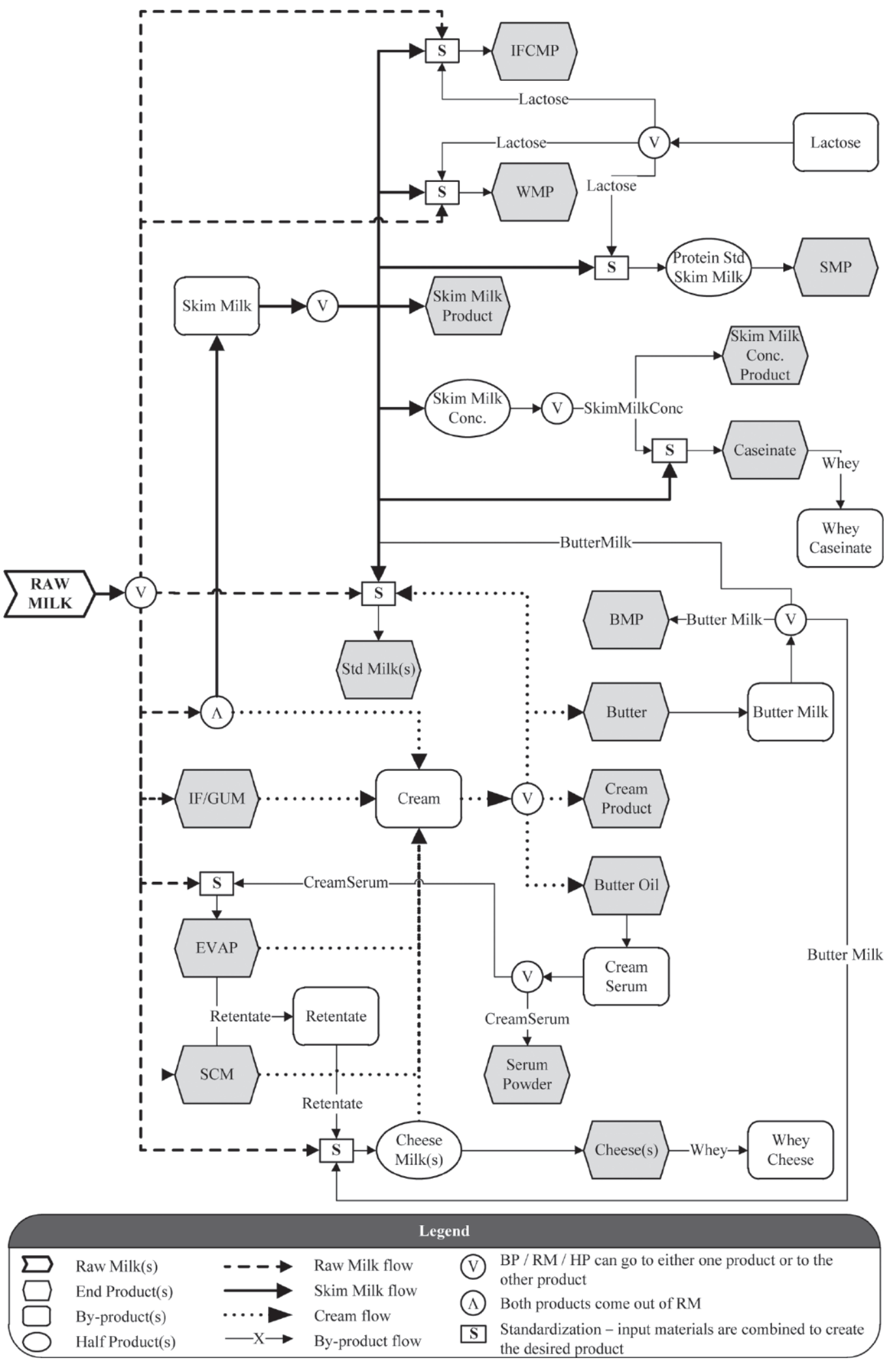

Figure 4. Dairy flows, based on Dairy Processing Handbook (Bylund, 2003) and discussions with experts. IFCMP = instant full cream milk powder; WMP $=$ whole milk powder; $\mathrm{SMP}=$ skim milk powder; StdMilks $=$ standardized milks; $\mathrm{BMP}=$ buttermilk powder; IF $/ \mathrm{GUM}=$ infant food and growing-up milk powder; EVAP = evaporated milk; SCM = sweetened condensed milk; $\mathrm{BP}=$ byproducts; $\mathrm{RM}=$ raw milk; HP $=$ half product. 
Table 4 . Indices used in the dairy valorization model

\begin{tabular}{ll}
\hline Index and set ${ }^{1}$ & Description \\
\hline$d, d^{\prime}, d^{\prime \prime} \in D$ & $D=$ dairy set that includes all products (raw milk, byproducts, half products, end \\
& products) \\
$e \in E$ & $E=$ set of end products, subset of dairy set $(E \subset D)$ \\
$b \in B$ & $B=$ set of byproducts, subset of dairy set $(B \subset D)$ \\
$h \in H$ & $H=$ set of half products, subset of dairy set $(H \subset D)$ \\
$m \in M$ & $M=$ set of raw milks, subset of dairy set $(M \subset D)$ \\
$i \in I$ & $I=$ set of recipes \\
$a \in I$ & $A=$ set of supply areas (regions) \\
$l, l^{\prime} \in L$ & $L=$ set of locations \\
$r \in R$ & $R=$ set of resources \\
$t r \in T R$ & $T R=$ set of tranches \\
$t \in T$ & $T=$ set of time periods (all set elements define the planning horizon) \\
\hline
\end{tabular}

${ }^{1}$ Indices with single and double primes belong to the same index set as the index without the prime. For example, $d, d^{\prime}$, and $d^{\prime \prime}$ represent 3 dairy products belonging to the same dairy set $D$.

of the DVM can then be used to create the operational production plans.

To create optimal mid-term production plans, original products are aggregated to 82 representative products (hereafter referred to as products). The input data of all original products related to demand and production are aggregated accordingly. All main dairy products are listed in Table 3. Although the table lists only 31 products, the product portfolio included in the model distinguishes between multiple foil cheeses (6), nature cheeses (11), foil cheese milks (11), nature cheese milks
(12), and standardized skim milks (16). Furthermore, a large group of whey-based products is represented in this study by cheese whey and casein whey products.

As mentioned previously, production processes of various products are interrelated, mainly because of $\mathrm{BP}$ reuse. Interrelations between dairy products are depicted in Figure 4. The figure shows only the internal flow of dairy products, but all products can additionally be purchased or sold on the market.

Dairy products can be produced at all $37 \mathrm{FC}$ production locations situated in Belgium, Germany, and

Table 5. Decision variables used in the dairy valorization model

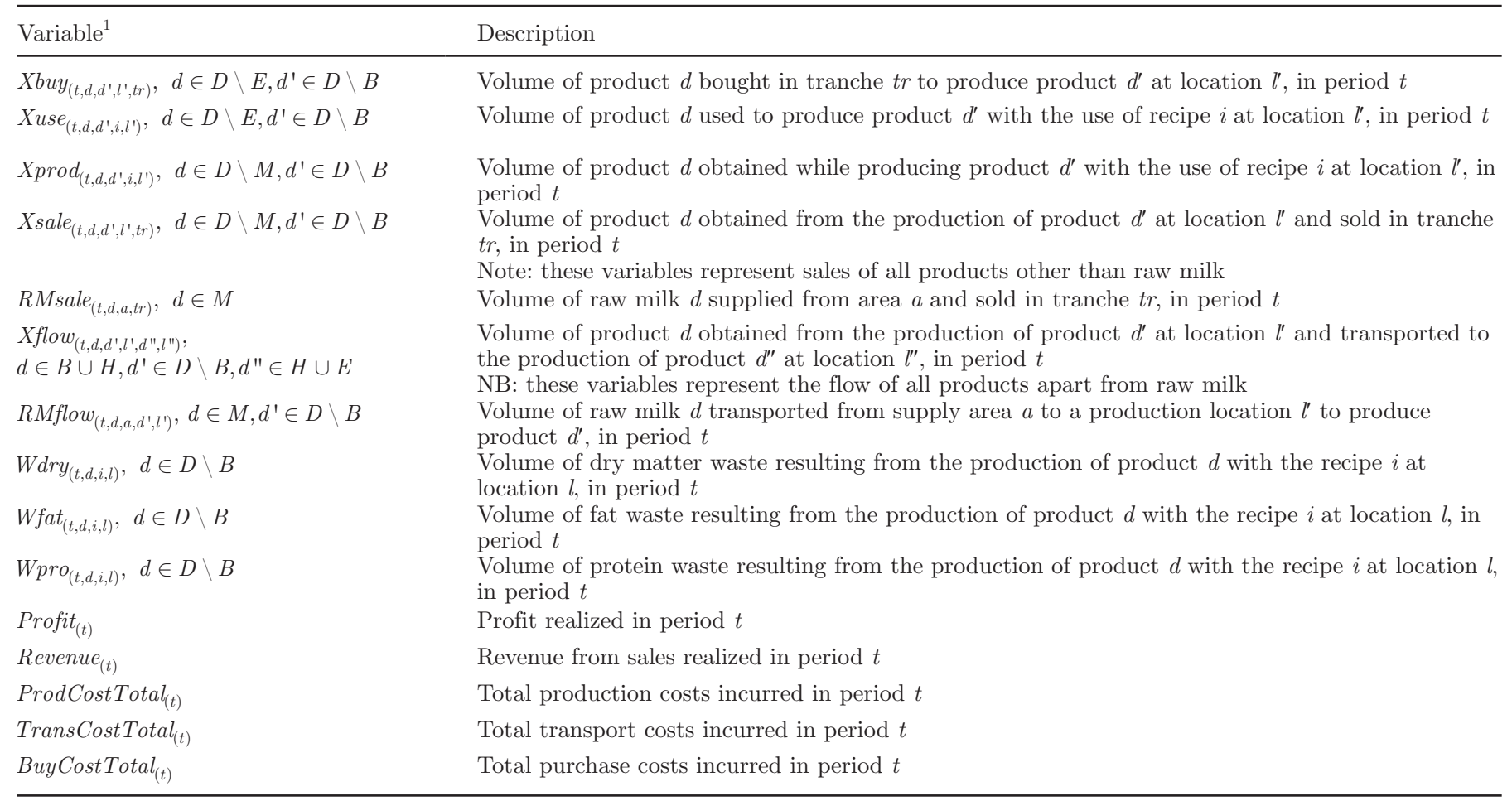

${ }^{1}$ The backslash symbol "\" indicates a set difference. Thus, $d \in D \backslash E$ defines all products $d$ that belong to set $D$ and do not belong to set $E$. 
Table 6. Parameters used in the dairy valorization model

\begin{tabular}{|c|c|c|c|}
\hline Parameter & Unit & Description & $\begin{array}{l}\text { Update } \\
\text { frequency }\end{array}$ \\
\hline Supply $_{(t, m, a)}$ & Tonne $(\mathrm{t})$ & Supply level of raw milk $m$ coming from supply area $a$ in period $t$ & Monthly \\
\hline MaxAddSale $_{(t, d)}$ & $\mathrm{t}$ & Maximum market capacity & Monthly \\
\hline MaxSale $_{(t, d, t r)}$ & $\mathrm{t}$ & Maximum sale volume of product $d$ that can be sold in tranche $t r$ in period $t$ & Monthly \\
\hline SalePrice $_{(t, d, t r)}$ & $€ / \mathrm{t}$ & Sale price of product $d$ that can be sold in tranche $t r$ in period $t$ & Monthly \\
\hline BuyPrice $_{(t, d, t r)}$ & $€ / \mathrm{t}$ & Purchase price of product $d$ that can be bought in tranche $t r$ in period $t$ & Monthly \\
\hline ResourceCap $_{(t, r, l)}$ & $\mathrm{h}$ & Capacity of resource $r$ in time period $t$ available at location $l$ & Monthly \\
\hline $\operatorname{Dry}_{(t, d)}$ & $\%$ & Dry matter content in product $d$ in period $t$ & Monthly \\
\hline$F a t_{(t, d)}$ & $\%$ & Fat content in product $d$ in period $t$ & Monthly \\
\hline $\operatorname{Pro}_{(t, d)}$ & $\%$ & Protein content in product $d$ in period $t$ & Monthly \\
\hline Distance $_{(t, d)}$ & $\mathrm{km}$ & Distance between production locations $l$ and $l^{\prime}$ & Yearly \\
\hline TransCost $_{(d)}$ & $€ / \mathrm{t} \cdot \mathrm{km}$ & Unit transport cost of product $d$ & Yearly \\
\hline ProdRate $_{(d, i, r)}$ & $\mathrm{t} / \mathrm{h}$ & Production rate of product $d$ produced with recipe $i$ at resource $r$ & Yearly \\
\hline $\operatorname{ProdCost}_{(d)}$ & $€ / \mathrm{t}$ & Unit production cost of product $d$ & Yearly \\
\hline
\end{tabular}

the Netherlands. The RM supply area is divided geographically -3 regions corresponding to 3 countries. To convert RM into EP, 22 resources (production equipment) are used. The produced products can be sold in 4 tranches, the first of which represents the contracted volumes (i.e., minimum sales). Maximum sales volume and selling price are assigned to every tranche.

\section{Mathematical Model Description}

The parameters in the DVM represent market and supply limitations, composition of products, production characteristics (e.g., recipes, production rates, and costs), and transport. The values of parameters are updated either once a year or every time the model is run (i.e., every month). Decision variables in the DVM represent volumes (tonnes), for example, used, produced, and transported. Indices used to create parameters and variables, decision variables, and enumerated parameters, as used in the equations below, are defined and presented in Table 4, Table 5, and Table 6, respectively. Indices with single and double primes belong to the same index set as the index without the prime symbols. For example, $d, d^{\prime}$, and $d^{\prime \prime}$ represent 3 dairy products belonging to the same dairy set $D$.

To create a reliable valorization model that correctly describes the reality of dairy manufacturing, several constraints were formulated. These constraints are related to market limitations, production limitations, recipes, and product flows. All constraints were formulated for each period $t$ and are presented below:

(a) Capacities: Capacity of a resource $r$ used to decompose RM or to produce products at a location $l$ should not exceed the maximum available capacity at that location:

$$
\begin{aligned}
& \sum_{i \in I}\left(\sum_{m \in M} \frac{\operatorname{Xuse}_{(t, m, m, i, l)}}{\operatorname{ProdRate}_{(m, i, r)}}+\sum_{d \in H \cup E} \frac{\operatorname{Xprod}_{(t, d, d, i, l)}}{\operatorname{ProdRate}_{(d, i, r)}}\right) \\
& \leq \operatorname{ResourceCap}_{(t, r, l)}, \forall r, \forall l, \forall t .
\end{aligned}
$$

(b) Supply volume of RM: The volume of RM $m$ sold or delivered to production locations should equal the volume of RM supplied from area $a$ :

$$
\begin{aligned}
& \sum_{l \in L} \sum_{d \in D \backslash B} \operatorname{RMflow}_{(t, m, a, d, l)} \\
& +\sum_{t r \in T R} \operatorname{RMsale}_{(t, m, a, t r)}=\operatorname{Supply}_{(t, m, a)}, \forall m, \forall a, \forall t .
\end{aligned}
$$

(c) Total sales volume: Total sold volume of a dairy product $d$ should not exceed the maximum sales volume: 
$\sum_{t r \in T R}\left(\sum_{a \in A} \operatorname{RMsale}_{(t, d, a, t r)}+\sum_{d^{\prime} \in D \backslash B} \sum_{l^{\prime} \in L} X_{s a l e_{\left(t, d, d^{\prime}, l^{\prime}, t r\right)}}\right)$

$\leq \min \left(\sum_{t r \in T R} \operatorname{MaxSale}_{(t, d, t r)}, \operatorname{Demand}_{(t, d)}+\operatorname{MaxAddSale}_{(t, d)}\right)$

$\forall d, \forall t$.

(d) Sales and purchase volumes per tranche (tr): The volume of a dairy product $d$ sold in the first tranche $(t r)$ should equal the volume fixed in contracts (maximum sales volume of tranche 1):

$\sum_{a \in A} \operatorname{RMsale}_{(t, d, a, t r)}+\sum_{d^{\prime} \in D \backslash B \backslash l^{\prime} \in L} X_{\text {sale }} \operatorname{lt}_{\left(t, d, d^{\prime}, l^{\prime}, t r\right)}=$ MaxSale $_{(t, d, t r)}$, $t r=1, \forall d, \forall t ;$

the volume of a dairy product $d$ sold in every residual tranche should not exceed the maximum sales volume of that tranche:

$\sum_{a \in A} \operatorname{RMsale}_{(t, d, a, t r)}+\sum_{d^{\prime} \in D \backslash B \backslash B} \sum_{l^{\prime} \in L} X \operatorname{sale}_{\left(t, d, d^{\prime}, l^{\prime}, t r\right)} \leq$ MaxSale $_{(t, d, t r)}$, tr $>1, \forall t r, \forall d, \forall t ;$

the volume of a dairy product $d$ bought in the first tranche should equal the volume fixed in contracts:

$$
\begin{aligned}
& \sum_{d^{\prime} \in D \backslash B} \sum_{l^{\prime} \in L} X_{b u y_{\left(t, d, d^{\prime}, l^{\prime}, t r\right)}}=\operatorname{MaxBuy}_{(t, d, t r)}, \\
& t r=1, \quad d \in D \backslash E, \forall d, \forall t ;
\end{aligned}
$$

and the volume of a dairy product $d$ bought in every residual tranche should not exceed the maximum purchase volume of that tranche:

$$
\begin{aligned}
& \sum_{d^{\prime} \in D \backslash B} \sum_{l^{\prime} \in L} X b u y_{\left(t, d, d^{\prime}, l^{\prime}, t r\right)} \leq \operatorname{MaxBuy}_{(t, d, t r)}, \\
& t r>1, \forall t r, d \in D \backslash E, \forall d, \forall t .
\end{aligned}
$$

(e) Recipes: The volume of a BP $b$ obtained from the production of EP $e$ at a location $l$ with a recipe $i$ should equal the multiplication between the volume of the EP $e$ produced and the fraction of that $\mathrm{BP} b$ obtained while producing $1 \mathrm{t}$ of the desired product $e$ :

$$
\begin{aligned}
& \operatorname{Xprod}_{(t, b, e, i, l)}=\text { FractionOut }_{(t, b, e, i)} \cdot \operatorname{Xprod}_{(t, e, e, i, l)}, \\
& \forall b, \forall e, \forall i, \forall l, \forall t ;
\end{aligned}
$$

the volume of a BP $b$ obtained from the decomposition of RM $m$ at a location $l$ with a recipe $i$ should equal the volume of RM $m$ decomposed times the fraction of that $\mathrm{BP} b$ obtained while decomposing $1 \mathrm{t}$ of $\mathrm{RM} m$ :

$$
\begin{aligned}
& \operatorname{Xprod}_{(t, b, m, i, l)}=\text { FractionOut }_{(t, b, m, i)} \cdot X_{\text {use }}(t, m, m, i, l) \\
& \forall b, \forall m, \forall i, \forall l, \forall t ;
\end{aligned}
$$

and the volume of an input material $d$ required for the production of a product $d^{\prime}$ at a location $l^{\prime}$ with a recipe $i$ should equal the volume of the product $d^{\prime}$ produced times the fraction of the input material $d$ required to produce $1 \mathrm{t}$ of desired product $d^{\prime}$ :

$$
\begin{aligned}
& \operatorname{Xuse}_{\left(t, d, d^{\prime}, i, l^{\prime}\right)}=\text { FractionIn }_{\left(t, d, d^{\prime}, i\right)} \cdot \operatorname{Xprod}_{\left(t, d^{\prime}, d^{\prime}, i, l^{\prime}\right)}, \\
& d \in D \backslash E, \forall d, d^{\prime} \in E \cup H, \forall d^{\prime}, \forall i, \forall l^{\prime}, \forall t .
\end{aligned}
$$

(f) Composition balance: The total content of dry matter (Dry), fat (Fat), or protein (Pro) in input materials used in the production of a dairy product $d^{\prime}$ at a location $l^{\prime}$ with the use of a recipe $i$ should equal the total content of that component in resulting products:

$$
\begin{aligned}
& \sum_{d \in D \backslash E} \operatorname{Dry}_{(t, d)} \cdot \text { Xuse }_{\left(t, d, d^{\prime}, i, l^{\prime}\right)} \\
& =\sum_{d \in D \backslash M} \operatorname{Dry}_{(t, d)} \cdot \operatorname{Xprod}_{\left(t, d, d^{\prime}, i, l^{\prime}\right)}+W d r y_{\left(t, d^{\prime}, i, l^{\prime}\right)}, \\
& d^{\prime} \in D \backslash B, \forall d^{\prime}, \forall i, \forall l^{\prime}, \forall t ;
\end{aligned}
$$

$$
\begin{aligned}
& \sum_{d \in D \backslash E} F_{(t, d)} \cdot \text { Xuse }_{\left(t, d, d^{\prime}, i, l^{\prime}\right)} \\
& =\sum_{d \in D \backslash M} F_{(t, d)} \cdot \operatorname{Xprod}_{\left(t, d, d^{\prime}, i, l^{\prime}\right)}+\operatorname{Wfat}_{\left(t, d^{\prime}, i, l^{\prime}\right)}, \\
& d^{\prime} \in D \backslash B, \forall d^{\prime}, \forall i, \forall l^{\prime}, \forall t ;
\end{aligned}
$$

$$
\begin{aligned}
& \sum_{d \in D \backslash E} \operatorname{Pro}_{(t, d)} \cdot \text { Xuse }_{\left(t, d, d^{\prime}, i, l^{\prime}\right)} \\
& =\sum_{d \in D \backslash M} \operatorname{Pro}_{(t, d)} \cdot \operatorname{Xprod}_{\left(t, d, d^{\prime}, i, l^{\prime}\right)}+\operatorname{Wpro}_{\left(t, d^{\prime}, i, l^{\prime}\right)}, \\
& d^{\prime} \in D \backslash B, \forall d^{\prime}, \forall i, \forall l^{\prime}, \forall t .
\end{aligned}
$$


(g) Inflow volumes: The volume of an input material $d$ used for the production of a dairy product $d^{\prime \prime}$ at a location $l^{\prime \prime}$ should equal the volume of that input material $d$ delivered to that location $l^{\prime \prime}$ plus the volume of that input material $d$ bought:

$$
\begin{aligned}
& \sum_{i \in I} \operatorname{Xuse}_{\left(t, d, d^{\prime \prime}, i, l^{\prime \prime}\right)}=\sum_{l^{\prime} \in L} \sum_{d^{\prime} \in D \backslash B} X \text { flow }_{\left(t, d, d^{\prime}, l^{\prime}, d^{\prime \prime}, l^{\prime \prime}\right)} \\
& +\sum_{a} \operatorname{RMflow}_{\left(t, d, a, d^{\prime \prime}, l^{\prime \prime}\right)}+\sum_{t r \in T R} \operatorname{Xbuy}_{\left(t, d, d^{\prime \prime}, l^{\prime \prime}, t r\right)}, \\
& d \in D \backslash E, d^{\prime \prime} \in D \backslash B, \forall t, \forall d, \forall d^{\prime \prime}, \forall l " .
\end{aligned}
$$

(h) Outflow volumes: The volume of a dairy product $d$ obtained while producing a product $d^{\prime}$ at a location $l^{\prime}$ should equal the volume of the dairy product $d$ send to the production of other products $d^{\prime \prime}$ at locations $l$ " plus the volume sold on the market:

$$
\begin{aligned}
& \sum_{i \in I} \operatorname{Xprod}_{\left(t, d, d^{\prime}, i, l^{\prime}\right)} \\
& =\sum_{l^{\prime \prime} \in L} \sum_{d^{\prime \prime} \in E \cup H} X \text { flow }_{\left(t, d, d^{\prime}, l^{\prime}, d^{\prime \prime}, l^{\prime \prime}\right)}+\sum_{t r \in T R} X_{t r} \operatorname{sale}_{\left(t, d, d^{\prime}, l^{\prime}, t r\right)}, \\
& d \in D \backslash M, d^{\prime} \in D \backslash B, \forall t, \forall d, \forall d^{\prime}, \forall l^{\prime} .
\end{aligned}
$$

The DVM maximizes the profit of a dairy processor. Consequently, the objective function incorporates sales revenues, production costs, transport costs, and purchase costs. The mathematical formulation is presented below:

$$
\begin{aligned}
& \operatorname{Profit}_{(t)}=\operatorname{Revenue}_{(t)}-\operatorname{ProdCostTotal}_{(t)} \\
& -\operatorname{TransCostTotal}_{(t)}-\operatorname{BuyCostTotal}_{(t)}, \forall t,
\end{aligned}
$$

where

$$
\begin{aligned}
& \text { Revenue }_{(t)} \\
& =\sum_{d \in D} \sum_{t r \in T R} \text { SalePrice }_{(t, d, t r)} \cdot\left(\begin{array}{l}
\sum_{a \in A} \text { RMsale }_{(t, d, a, t r)} \\
+\sum_{l^{\prime} \in L} \sum_{d^{\prime} \in D \backslash B} X_{\text {sale }_{\left(t, d, d^{\prime}, l^{\prime}, t r\right)}}
\end{array}\right), \forall t ; \\
& \operatorname{ProdCostTotal}_{(t)}=\sum_{d \in D \backslash M} \operatorname{ProdCost}_{(d)} \cdot \sum_{d^{\prime} \in D \backslash B} \sum_{i \in I} \sum_{l^{\prime} \in L} \operatorname{Xprod}_{\left(t, d, d^{\prime}, i, l^{\prime}\right)} \\
& +\sum_{m \in M} \operatorname{ProdCost}_{(m)} \cdot \sum_{i \in I} \sum_{l^{\prime} \in L} \operatorname{Xuse}_{\left(t, m, m, i, l^{\prime}\right)}, \forall t ;
\end{aligned}
$$

$\operatorname{TransCostTotal}_{(t)}$
$=\sum_{d \in D \backslash E} \operatorname{Trans}_{\operatorname{Cost}} \cdot \sum_{(d)} \sum_{d^{\prime \prime} \in D \backslash B}\left(\begin{array}{l}\sum_{l^{\prime \prime} \in L} \sum_{d^{\prime} \in D \backslash B} X_{l^{\prime} \in L} \operatorname{flow}_{\left(t, d, d^{\prime}, l^{\prime}, d^{\prime \prime}, l^{\prime \prime}\right)} \\ +\sum_{a \in A} R M f l o w_{\left(t, d, a, d^{\prime \prime}, l^{\prime \prime}\right)}\end{array}\right)$,

$\forall t ;$

$\operatorname{BuyCostTotal}_{(t)}$

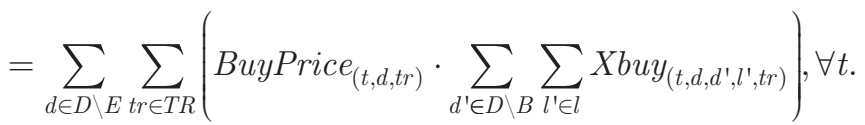

The formulated model was implemented in optimization software package called AIMMS 3.11 (Paragon Decision Technology B.V., Haarlem, the Netherlands). The model enables us to optimize production decisions for all 82 products. The outcome of the model provides good insight into various fields of attention; for example, produced volumes, capacity use, BP use, and components use. The DVM can also be used for milk valorization at other dairy companies because the dairy product portfolio is standardized throughout the world. Moreover, the developed model is flexible in terms of inputs used; thus, it can be adjusted easily to suit dairy production at other dairy companies.

\section{RESULTS AND DISCUSSION}

In this section, we will present numerical results of the study; however, detailed results cannot be provided because of confidentiality of data from FC. First, we will discuss the main results of the valorization plan, and then we will illustrate the impact of seasonality on RM components (i.e., the effect of yearly variation in $\mathrm{DM}$, fat, and protein contents of RM) on milk valorization. Both steps are carried out to show the comprehensiveness and correctness of the model and the type of information that can be extracted from the results. Finally, we will discuss the management implications of the DVM and provide directions for further research.

\section{Main Outcome}

The main valorization plan was created using original data supplied by FC. The planning horizon consisted of 12 mo (periods). The model was solved in $9 \mathrm{~s}$ on a computer with a $3-\mathrm{GHz}$ processor and $2 \mathrm{~GB}$ 


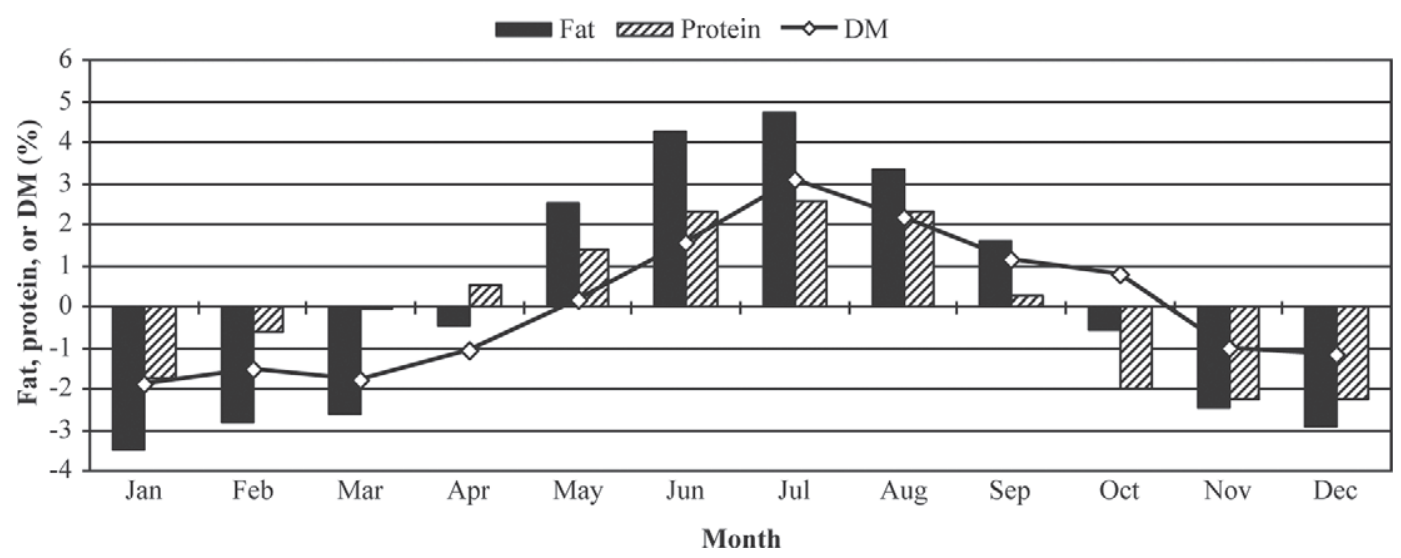

Figure 5. Relative percentage changes in the content of fat, protein, and DM in raw milk between 2 scenarios: scenario (S) with seasonal raw milk components and scenario (NS) with raw milk components fixed to the level of yearly averages. The following measure is used: (NS - S)/S.

of memory. The numbers of variables and constraints were 61,645 and 32,635 , respectively. The output of the model provided a valorization plan for every month in the planning horizon and delivered a good overview of the production, use, purchase, sales, and transportation volumes on different levels. For instance, looking at the production of EP, information can be decomposed into production per month, production per recipe, and production per location. Looking at BP use, the information on total use can be decomposed into the same information as for EP, and additionally into purchased volume, delivered volume, production location, and source products. Therefore, the model makes it possible to determine, among other factors, the following: (1) volume of BP obtained from and used for the production of an EP with the use of a certain recipe, at a certain location; (2) the part of the produced (used) BP volume that was shipped (delivered) to another location and the part that was sold (purchased) on the market; (3) volume of EP sold per tranche; (4) volume of input materials purchased per tranche; and (5) capacity use at production locations.

The results of the model were presented to and discussed with planners and managers of FC. The valorization plan was acknowledged not only as a realistic plan, but also as an optimal plan. This assessment was based on the experience of the FC employees and on outputs of current planning tools. Based on these discussions, we concluded that the DVM is a promising planning tool for the valorization of RM at FC.

\section{Effect of RM Seasonality}

The comprehensiveness and functionality of the DVM can be presented by assessing the consequences of changes in various input parameters. One can conduct different analyses that would evaluate, for instance, the profitability of additional available capacities versus investment costs, consequences of possibly inaccurate sales forecasts (effect of change in price), and the impact of a greater or lesser milk supply. We decided, however, to investigate the effect of seasonality of RM components on milk valorization. We found this aspect to be the most interesting for the following reasons: (1) production recipes are dynamic because they depend on variable milk composition, (2) most models available in the literature do not base recipes on milk components (see Table 2), (3) the composition of milk changes during the year, and (4) abolition of the quota system may result in even greater variation in milk composition. The analysis presented in this section not only illustrates the functionality of the DVM, but also emphasizes the importance of basing production recipes on milk components.

In models that do not base recipes on the seasonal composition of milk, ratios between RM, EP, and BP are fixed, but in reality, this is not true. Therefore, construction of a scenario with fixed composition of milk results in fixed ratios (thus, imitating models that do not base recipes on components). The differences between the 2 scenarios indicate the consequences of not accounting for seasonal milk components. Consequently, to evaluate the effect of seasonality on valorization plans, we prepared 2 scenarios: one that incorporated seasonality of RM components (S) and one that excluded the seasonality of components (NS). In scenario $\mathrm{S}$, the composition of milk varies throughout the year, and here the actual percentages of RM components were used. In contrast, in the NS scenario, the percentages of components are assumed constant throughout the year. These constant values are equal to the level of the yearly average of every component. Consequently, the contents of DM, fat, and protein in the NS scenario were $13.16,4.37$, and $3.51 \%$, respectively. Furthermore, 


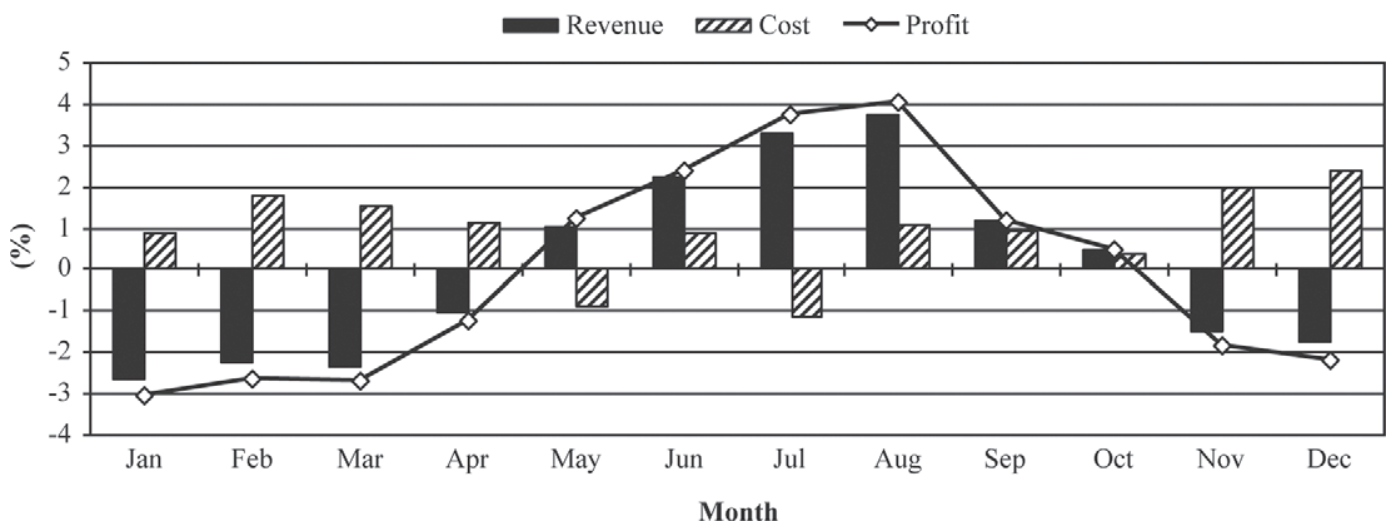

Figure 6. Relative percentage changes in revenue, costs, and profit between 2 scenarios: scenario (S) with seasonal raw milk components and scenario (NS) with raw milk components fixed to the level of yearly averages. The following measure is used: (NS - S)/S.

in both scenarios, we included the possibility of selling additional volumes of commodity EP. Commodities are products that can be sold on an unlimited world market. The relative percentage difference was used to compare the results of both scenarios and was calculated as $(\mathrm{NS}-\mathrm{S}) / \mathrm{S}$. The relative percentage differences in the composition of RM are depicted in Figure 5. As can be seen, the level of components was lower in scenario NS in the first and last months of the year, meaning that $\mathrm{DM}$, fat, and protein contents in RM were higher than the yearly average in these months.

Differences between scenario profit levels, BP use and production, and EP volumes illustrate the effect of seasonality on valorization plans. Analysis of the differences also shows the potential of the model with regard to extracting information important for performance improvement. To provide an overview of results, RM and EP were grouped into several clusters. Aggregation was made based on the similarities in input materials used for the production of products. The following clusters were created: (1) caseinates (caseinate roller and caseinate spray); (2) cheeses (all foil and nature cheeses); (3) condensed milks (evaporated milk and sweet condensed milk); (4) cream powders (butter milk powder and serum powder); (5) cream products (butter, butteroil, and cream products); (6) infant powder (infant food and growing-up milk powder, IF/GUM); (7) milk powders (SMP and whole milk powder); (8) decomposition (RM); and (9) all standardized milks (StdMilks). Byproducts and HP were not directly assigned to clusters. The production and use volumes of BP per cluster were calculated based on EP cluster allocation. Furthermore, volumes of input materials used for the production of HP were assigned to EP, and thus to clusters, based on recipes. For instance, the volume of RM used for the production of cheese milk, which

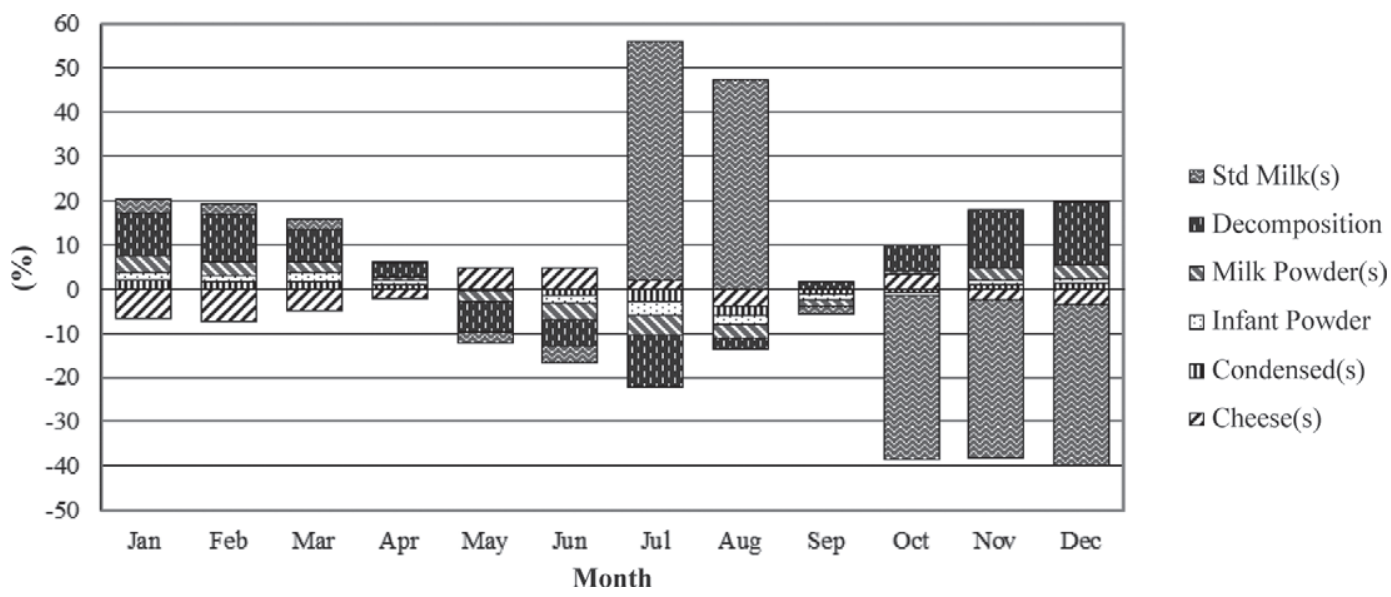

Figure 7. Relative percentage changes in the allocation of raw milk to clusters between 2 scenarios: scenario $(\mathrm{S})$ with seasonal raw milk components and scenario (NS) with raw milk components fixed to the level of yearly averages. The following measure is used: (NS - S)/S. Std Milk = standardized milks. 


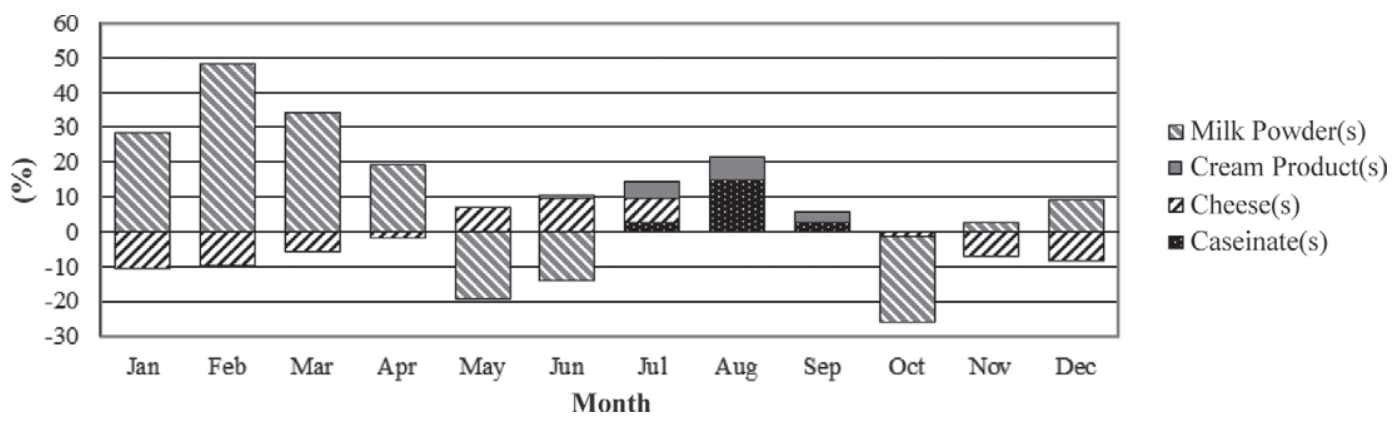

Figure 8. Relative percentage changes in the volume of end products produced per cluster between 2 scenarios: scenario (S) with seasonal raw milk components and scenario (NS) with raw milk components fixed to the level of yearly averages. The following measure is used: (NS - S)/S.

is required to produce a certain cheese, was included in the cheeses cluster. The decomposition cluster represents decomposed RM volumes as well as the resulting cream and skim milk volumes.

Relative percentage profit changes between 2 scenarios are depicted in Figure 6. The changes in profit and revenue followed a pattern very similar to that of relative percentage changes in RM composition (Figure 5). The profit of scenario NS was lower in the first and last months of the year. This can be explained by the differences in RM composition that influence compositionbased recipes. The volume of input material required for the production of a certain product depends on the content of DM, fat, or protein in that EP and in all input materials. Therefore, depending on the component levels in RM, different volumes of EP can be obtained from $1 \mathrm{t}$ of RM. For instance, the percentage difference between scenarios in the volume of milk required to produce $1 \mathrm{t}$ of IF/GUM product (infant powder cluster) varied between -3.0 and $+1.9 \%$. In a situation in which more milk is required to produce $1 \mathrm{t}$ of IF/GUM, less milk is available for the production of other products, and consequently profit in this month would be lower. In the first and last months of the year, component levels in RM were higher than the yearly average. In these months, it is possible to produce larger quantities of profitable products and therefore reach higher profits (scenario S).

The effect of seasonality was well reflected in decisions regarding the allocation of RM to clusters, and thus in the production of EP per cluster. In Figures 7 and 8, percentage changes in RM allocation and EP production are presented per cluster. The shift in RM is reflected in the shift of EP only into 2 clusters - milk powders and cheeses. This means that the allocation of larger or smaller volumes of RM to clusters StdMilks, infant powder, and condensed milks is driven only by the change in RM composition, not by the profitability of products. Different RM compositions affect the choice of recipe that is used to produce a certain product as well as the volume of $\mathrm{RM}$ required to produce $1 \mathrm{t}$ of EP. The change in the allocation of RM to the cluster decomposition is driven mainly by the end production requirement for skim milk and cream. Figures 9 and 10 depict relative percentage changes in skim milk and cream use and production. The differences in RM use in the decomposition cluster (see Figure 7) are reflected in the production of cream and skim milk in that cluster (Figure 9 and Figure 10). Furthermore, a very large percentage change occurred in skim milk and cream

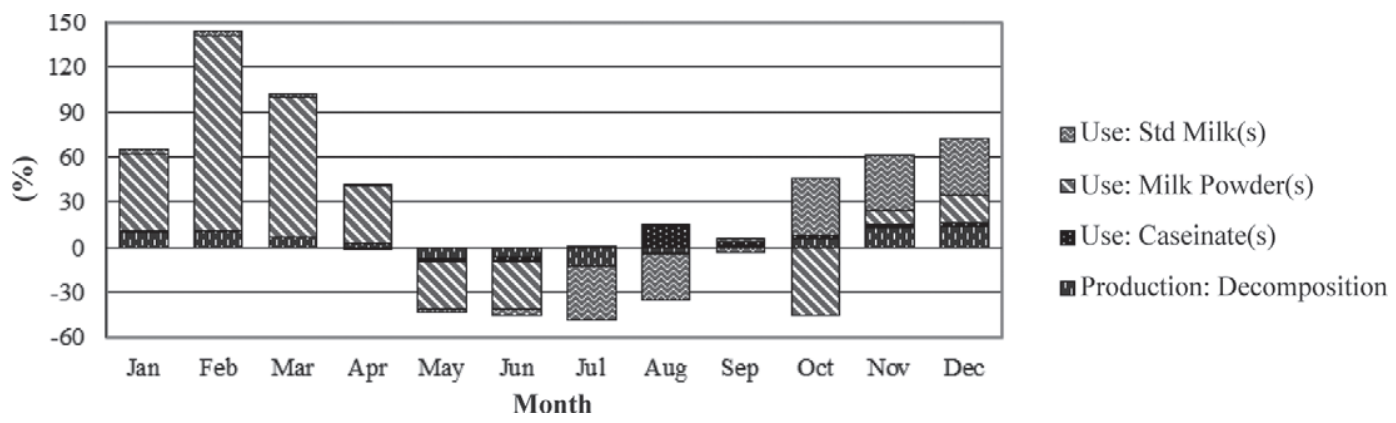

Figure 9. Relative percentage changes in skim milk use and production per cluster between 2 scenarios: scenario (S) with seasonal raw milk components and scenario (NS) with raw milk components fixed to the level of yearly averages. The following measure is used: (NS - S)/S. $\operatorname{StdMilk}(\mathrm{s})=$ standardized milks. 


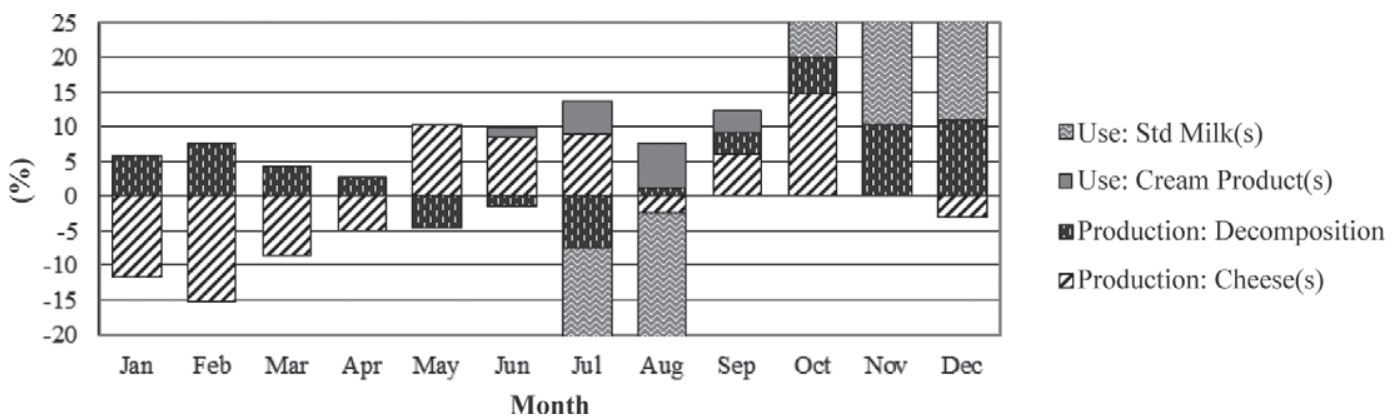

Figure 10. Relative percentage changes in cream use and production per cluster between 2 scenarios: scenario (S) with seasonal raw milk components and scenario (NS) with raw milk components fixed to the level of yearly averages. The following measure is used: (NS - S)/S. $\operatorname{StdMilk}(\mathrm{s})=$ standardized milks.

use in the StdMilks cluster, following a change in the recipe used to produce these EP. For instance, looking at July, much higher volumes of RM and much lower volumes of cream and skim milk were used in scenario NS to produce products in the StdMilks cluster. In that month, a recipe that uses RM and buttermilk would be favored over a recipe that uses cream and skim milk.

Figure 8 shows that differences in end production volumes exist between caseinates, cheeses, cream products, and milk powders clusters. Changes in these particular clusters can be explained by the need to fulfill various constraints, change in product profitability, and assignment of specialties to clusters. Specialties are products that can be sold only as demand-driven products. Consequently, from the perspective of EP, no change occurred in produced volumes of specialties. From the RM perspective, the change in composition only affected the volume of input materials required to produce these specialties. Figure 8 shows that, almost in all months, RM is reallocated between production of various cheeses (cheeses cluster) and the production of SMP (milk powders cluster). A relatively small decrease in cheese production leads to a significantly large increase in SMP production. For instance, looking at February, $10 \%$ lower production of cheese in the scenario NS leads to $50 \%$ higher production of SMP. Given the fact that, in the current data set, cheese products are more profitable than milk powder products, such a reallocation of RM would have a negative effect on the overall profit of the company (Figure 6). Analyses showed that the shift in production of cheese products and SMP was driven by the cream volume required to fulfill constraints (i.e., minimum sales of cream-based EP). In other words, the volume of cream that can be obtained from $1 \mathrm{t}$ of $\mathrm{RM}$ allocated to the production of cheese is, on average, lower than the volume of cream that can be obtained from the decomposition of $1 \mathrm{t}$ of RM. Therefore, in months when production of cheese products is lower, smaller volumes of RM are used to produce cheeses, and thus larger volumes of RM are available for the decomposition. Thus, a sufficient volume of cream is obtained to produce contracted cream-based products. The second residual byproduct of decomposition, skim milk, is allocated to SMP production. In months in which a sufficient volume of cream is available in the milk system (i.e., from May to September), additional volumes of products are produced in the cheeses, cream products, and caseinates clusters. The shift in the production of EP presented in Figure 8 is also reflected in the change in the RM composition presented in Figure 5. In months when the fat content of RM is higher than the yearly average, more cheese and cream-based products are produced.

\section{Management Implications}

The use of the DVM model within a dairy company has some advantages. It is difficult, however, to express the added value in monetary terms. Nevertheless, we can enumerate several benefits of using the model. The following management implications are the result of final sessions held with experts, during which outcomes of the DVM and different ways of using them to support the decision-making processes within the company were discussed. First, in large companies such as FC, a wide range of EP is produced. Products are produced by specialized operating companies $(\mathbf{O p C o})$ that belong to the company. For instance, one OpCo can be responsible for production of cheeses and another for production of powders. Every OpCo has a certain demand for RM. Fulfilling the demands of all OpCos might not be the most optimal solution, because no attention is paid to the resulting BP. Without an appropriate model, it is very difficult to assess the effect of fulfilling the demand of one OpCo on the production of another OpCo. A mid-term allocation and production-planning model such as the DVM allows simultaneous optimization of the whole system. The inclusion of all relevant elements 
in the model provides necessary links between different OpCos. Second, the large amount of information explains the dynamics and interrelations between OpCos, and can be used to improve the communication within the company. The central department responsible for integrated milk allocation and valorization could use the model to support their allocation decisions. Third, the information on limited production of profitable products can indicate scarce input materials or limited capacity. This can trigger changes, for example, in purchase and sale strategies or in capacity investment plans. Fourth, the flexibility of the model, in terms of parameters, allows various analyses: the model could be used to explore ideas or plans related to sales strategies, capacity and technology investments, or facility locations. To summarize, comprehensive valorization plans provide managers with information necessary not only for professional production planning, but also for effective dairy supply chain management. The DVM described here is, therefore, a promising decision-support tool.

\section{Future Research}

Although many aspects allowing for successful valorization of milk were included in the DVM, further improvements are possible. In the case study presented here, inventory policies were included in the input data. One of the possible model extensions would be the inclusion of inventory management options. Further, all parameters in our model were treated as deterministic. Given the fluctuations in supply and demand, especially when looking more than 6 mo ahead, stochastic methods might be considered to model related input parameters. Moreover, in this study, we incorporated only 2 types of whey (cheese whey and casein whey). As cheeses constitute a large part of every dairy processor's product portfolio, and thus large volumes of whey byproduct are obtained, a detailed investigation of whey postprocessing might allow better valorization of RM. Finally, the presented work does not incorporate analyses on the robustness of valorization plans. Outcomes of such a study would indicate elements with the greatest effect on valorization plans.

\section{CONCLUSIONS}

The DVM was developed to improve mid-term milk valorization, defined as the optimal allocation of RM and production planning of BP and EP. The necessity for such a model was driven by the interrelated dairy production processes that complicate decision making related to the allocation of milk. Volatile market conditions and some specific characteristics of dairy supply chains add complexity. A comprehensive model should include all relevant elements that affect milk valorization (i.e., production recipes based on RM composition, seasonality of RM supply and composition, interrelations in production due to BP utilization, complete production portfolio, network of supply regions, and production locations). The model should facilitate understanding of the dynamics of dairy production, thereby assisting management. The model was tested at one of the world largest dairy producers - Friesland Campina - and the structure and outputs of the model were discussed during iterative sessions with dairy supply chain managers, production planners, technologists, and market analysts at FC. Several possible benefits from using the model were indicated: (1) optimal allocation of milk, (2) improvement of communication between central planning department and various operational units, (3) an "early warning" system of upcoming developments affecting production, (4) ability to prepare for changing market conditions, and (5) ability to explore ideas and plans related to investment strategies.

\section{REFERENCES}

Adonyi, R., E. Shopova, and N. Vaklieva-Bancheva. 2009. Optimal schedule of a dairy manufactory. Chem. Biochem. Eng. Q. 23:231-237.

Ahumada, O., and J. R. Villalobos. 2009. Application of planning models in the agri-food supply chain: A review. Eur. J. Oper. Res. 196:1-20.

Benseman, B. R. 1986. Production planning in the New Zealand dairy industry. J. Oper. Res. Soc. 37:747-754.

Bilgen, B., and I. Ozkarahan. 2004. Strategic tactical and operational production-distribution models: A review. Int. J. Technol. Manag. 28:151-171.

Budai, G., R. Dekker, and R. P. Nicolai. 2008. Maintenance and production: A review of planning models. Pages 321-344 in Complex System Maintenance Handbook. K. A. H. Kobbacy and D. N. Prabhakar Murthy, ed. Springer, London, UK.

Burke, J. A. 2006. Two mathematical programming models of cheese manufacture. J. Dairy Sci. 89:799-809.

Bylund, G. 2003. Dairy Processing Handbook. Tetra Pak Processing Systems AB, Lund, Sweden.

Chen, Z. L. 2004. Integrated production and distribution operations: Taxonomy, models, and review. Pages 711-746 in Handbook of Quantitative Supply Chain Analysis: Modeling in the E-Business Era. D. Simchi-Levi, S. D. Wu, and Z.-J. Shen, ed. Kluwer Academic Publishers. Amsterdam, the Netherlands.

Craig, K. L., J. P. Norback, and M. E. Johnson. 1989. A linear programming model integrating resource allocation and product acceptability for processed cheese products. J. Dairy Sci. 72:30983108.

Doganis, P., and H. Sarimveis. 2007. Optimal scheduling in a yogurt production line based on mixed integer linear programming. J. Food Eng. 80:445-453.

Doganis, P., and H. Sarimveis. 2008. Optimal production scheduling for the dairy industry. Ann. Oper. Res. 159:315-331.

FrieslandCampina. 2011. Annual report 2011. Royal FrieslandCampina, Amersfoort, the Netherlands.

Geary, U., N. Lopez-Villalobos, D. J. Garrick, and L. Shalloo. 2010. Development and application of a processing model for the Irish dairy industry. J. Dairy Sci. 93:5091-5100. 
Guan, Z., and A. B. Philpott. 2011. A multistage stochastic programming model for the New Zealand dairy industry. Int. J. Prod. Econ. 134:289-299.

Johnson, H. A., L. Parvin, I. Garnett, E. J. DePeters, J. F. Medrano, and J. G. Fadel. 2007. Valuation of milk composition and genotype in cheddar cheese production using an optimization model of cheese and whey production. J. Dairy Sci. 90:616-629.

Kerrigan, G. L., and J. P. Norback. 1986. Linear programming in the allocation of milk resources for cheese making. J. Dairy Sci. 69:1432-1440.

LTO. 2011. International comparison of producer prices for milk, 2010 Land- en Tuinbouw Organisatie (LTO) Nederland, The Hague, the Netherlands.

Lutke-Entrup, M., H. O. Gunther, P. Van Beek, M. Grunow, and T. Seiler. 2005. Mixed-integer linear programming approaches to shelf-life-integrated planning and scheduling in yoghurt production. Int. J. Prod. Res. 43:5071-5100.

Mellalieu, P. J., and K. R. Hall. 1983. An interactive planning mode for the New Zealand dairy industry. J. Oper. Res. Soc. 34:521532 .

Mula, J., D. Peidro, M. Diaz-Madronero, and E. Vicens. 2010. Mathematical programming models for supply chain production and transport planning. Eur. J. Oper. Res. 204:377-390.

Mula, J., R. Poler, J. P. Garcia-Sabater, and F. C. Lario. 2006. Models for production planning under uncertainty: A review. Int. J. Prod. Econ. 103:271-285.
Papadatos, A., A. M. Berger, J. E. Pratt, and D. M. Barbano. 2002 A nonlinear programming optimization model to maximize net revenue in cheese manufacture. J. Dairy Sci. 85:2768-2785.

Roupas, P. 2008. Predictive modelling of dairy manufacturing processes. Int. Dairy J. 18:741-753.

Sahinidis, N. V. 2004. Optimization under uncertainty: State-of-theart and opportunities. Comput. Chem. Eng. 28:971-983.

Vaklieva-Bancheva, N., A. Espuna, E. Shopova, L. Puigjaner, and B. Ivanov. 2007. Multi-objective optimization of dairy supply chain. Computer-Aided Chem. Eng. 24:781-786.

Vidal, C. J., and M. Goetschalckx. 1997. Strategic production-distribution models: A critical review with emphasis on global supply chain models. Eur. J. Oper. Res. 98:1-18.

Wazed, M. A., S. Ahmed, and Y. Nukman. 2010. A review of manufacturing resources planning models under different uncertainties: State-of-the-art and future directions. S. Afr. J. Indust. Eng. $21: 17-33$

Womach, J. 2005. Agriculture: A Glossary of Terms, Programs, and Laws. 2005 ed. Congressional Research Service, Washington, DC.

Wouda, F. H. E., P. van Beek, J. G. A. J. van der Vorst, and H. Tacke. 2002. An application of mixed-integer linear programming models on the redesign of the supply network of Nutricia Dairy \& Drinks Group in Hungary. Spectrum 24:449-465. 